University of Nebraska - Lincoln

DigitalCommons@University of Nebraska - Lincoln

1976

\title{
Reflectant Induced Modification of Soybean Canopy Radiation Balance. IV. Leaf and Canopy Temperature
}

M. W. Baradas

B. L. Blad

University of Nebraska - Lincoln

N. J. Rosenberg

Follow this and additional works at: https://digitalcommons.unl.edu/natrespapers

Part of the Natural Resources and Conservation Commons, Natural Resources Management and Policy Commons, and the Other Environmental Sciences Commons

Baradas, M. W.; Blad, B. L.; and Rosenberg, N. J., "Reflectant Induced Modification of Soybean Canopy Radiation Balance. IV. Leaf and Canopy Temperature" (1976). Papers in Natural Resources. 1185. https://digitalcommons.unl.edu/natrespapers/1185

This Article is brought to you for free and open access by the Natural Resources, School of at DigitalCommons@University of Nebraska - Lincoln. It has been accepted for inclusion in Papers in Natural Resources by an authorized administrator of DigitalCommons@University of Nebraska - Lincoln. 


\title{
Reflectant Induced Modification of Soybean Canopy Radiation Balance IV. Leaf and Canopy Temperature
}

\author{
Maximo W. Baradas, Blaine L. Blad, and Norman J. Rosenberg²
}

\section{ABSTRACT}

Potential water-savings and increased water use efficiency may result from reflectant-induced modification of the canopy radiation balance. This report is the fourth in a series of papers describing reflectant treatment effects on the radiation balance. The purpose of this study was to determine the effect of reflectant treatment on the leaf and canopy temperature of two soybean [Glycine max (L.) Merr] cultivars which display contrasting types of canopy architecture. 'Amsoy' and 'Beeson' which have erectophile and planophile canopies, respectively, werc used. Leaf temperature was measured with leaf thermocouples and canopy temperature with an infrared thermometer.

Near solar noon, the reflectorized Amsoy canopy was 1 to 2 C warmer than the untreated canopy. Smaller but qualitatively similar differences were observed in the Beeson cultivar. Whether reflectorized or not, the Amsoy canopies were warmer than the corresponding Beeson canopies. The increased temperature of the treated plants was corroborated by thermal imagery from an airborne scanner.

The unexpected temperature increase of the reflectorized crop was due to two major factors. The first, and probably most important, was a decrease in the longwave emissivity of the treated crop. This, in turn, caused reduced cooling rates and also caused the absorptivity to emissivity ratio $(\alpha / \varepsilon)$ to be increased. The second factor was reduced transpiration rates which were observed for the reflectorized crop.

Additional index words: Crop emissivity, Longwave radiation, Glycine $\max$ (L.) Merr.
R EFLECTANTS applied to crops should increase reflection of incoming solar radiation and thus clecrease net radiation. In two of the previous papers in this series (Doraiswamy and Rosenberg, 1974; Lemeur and Rosenberg, 1975) it was shown that reflectant treatment of a soybean [Glycine $\max$ (L.) Merr.] canopy does, indeed, increase shortwave (global radiation) reflection and decrease net radiation. Seginer (1969) predicted that an increase in shortwave reflection coefficient of an irrigated field from 0.25 to 0.40 would result in a $30^{\circ}$; reduction in both net radiation and water use. Rosenberg and Brown (1973), using at resistance analogy of evapotranspiration, also predicted that a reduction in net radiation would result in significant water savings.

While the effect of a reflectant on the shortwave radiation balance is already clear, reflectant influence on the longwave balance is not yet well understood.

\footnotetext{
' Published as Paper No. 3985, Journal Series, Nebraska Agric. Exp. Stn. The work reported was conducted under Nebraskz Agric. Exp. Stn, Project No. 20-31 and Regional Research Project 11-33. Information in this paper was presented at the Innual Mecting, American Society of Agronomy, Chicago, Ill., 10-I2 Nov. 1974. Received 23 Apr. 1975.

- Research associate, assistant professor, and professor, Agricultural Mcteorology Section, Dep. of Agric. Eng., Institute of igric. and Natural Resources, University of Nebraska-Lincoln, Lincolı, N'E 68583.
} 
The outgoing longwave radiation from a crop canopy $(\mathrm{LW} \uparrow)$ is:

$$
\mathrm{LW}+=\varepsilon_{\mathrm{c}} \sigma \mathrm{T}^{4}+\left(1-\varepsilon_{\mathrm{c}}\right) \mathrm{LW} \downarrow
$$

where $\varepsilon_{\mathrm{c}}$ is the emissivity, $\sigma$ is the Stefan-Boltzmann constant, $T$ is the absolute temperature $(K)$ of the crop surface and LW $\downarrow$ is incoming longwave radiation. Any change in the emissivity of the crop and/or its temperature will alter the flux density of LW 4 .

Emissivity of crops in the 8 to $14 u$ wavelength band is reported to range from about 0.95 to 0.98 (Gates and Tantraporn, 1952; Sellers, 1965, p. 41; Fuchs and Tanner, 1966: Bartholic et al., 1972). Emissivity of materials which may serve as reflectants is generally lower (Hudson, 1969, p. 44). Thus the emissivity of a reflectorized crop canopy should be intermediate between that of an untreated crop canopy and that of the reflectant.

The lowered emissivity of a reflectorized crop means that the reflection of the incoming longwave radiation is increased. At the same time, however, lowered emissivity reduces the rate of radiative cooling. These two processes have opposite effects on the crop temperature. Increased reflection tends to reduce the canopy temperature whereas reduced radiative cooling should increase it.

Evapotranspiration, a cooling process, is also a factor which controls canopy temperature. If evapotranspiration from a canopy is reduced by reflectant treatment, the canopy temperature should rise. Reduced transpiration may occur as a result of direct blockage of the stomates by the reflectant or as a result of reduced radiant energy absorption when a large portion of the incident shortwave radiation is reflected.

In this paper we present data on the effects of reflectants on the temperature of a crop canopy. In a companion paper (Baradas et al., 1976), we discuss reflectant effects on the longwave radiation balance. To explain the observed effects we propose, in the latter paper, a mechanism of the energy balance modification by reflectants.

\section{MATERIAL AND METHODS}

Plot Design. The 'Amsoy' cultivar of soybean was seeded in the west half of a $20 \times 110 \mathrm{~m}$ north-south oriented field at the Univ, of Nebraska Agricultural Meteorology Research Lab. at Nead, Nebraska $\left(41^{\circ} 09^{\prime} \mathrm{N}, 96^{\circ} 30^{\circ} \mathrm{W} ; 347 \mathrm{~m}\right.$ above MSL) on 25 May 1973. The east half of the field was planted to the 'Beeson' cultivar. Rows were oriented north-south on $46 . \mathrm{cm}$ centers. Plants were spaced about $4 \mathrm{~cm}$ apart in the rows. The field was not irrigated. Because of ample rainfall during 1973, neither cultivar displayed any noticeable moisture stress during the growing season.

Portions of the field planted to each cultivar were coated with reflectant on 28 July and again on 8 August. Designated plots, each $8.2 \times 10.1 \mathrm{~m}(0.008 \mathrm{ha})$, were established so that four treatments resulted: Amsoy Treated (reflectorized), Amsoy Untreated, Beeson Treated, and Beeson Untreated (Fig. 1). Similar treatments were also applied on much larger plots in an adjacent field. A portion of that field can be seen to the right of the labeled plots.

Reflectant Application. The reflectant was Celite $209^{3}$ which was sprayed onto the crop in a slurry mixture consisting of 26.5

". I dialomaceous earth obtained from Johns-Mranville Products Corp., P.O. Box 2598, Denver, CO 80201 .

IIcer Corp., 9500 Railroald Ive., North Bergen, NJ 07047.

$\therefore$ Ruger Chemical Co., Inc., P.O. Box 806, Hillside, NJ 07205.

"Rarliator Specialty Co., Challote, N.C. Part No. M-4-12.

`Hannes Eng. Co., 30 Commerce Road, Stamford, CT 06902. g Celite 209, $3.7 \mathrm{ml} \mathrm{95 \%} \mathrm{ethyl} \mathrm{alcohol,} 2.7 \mathrm{~g}$ gum guar (sticker)4, and $1.3 \mathrm{ml}$ Tween-20 (surfactant) ${ }^{5}$ per liter of water. The gum was dissolved in the ethyl alcohol before being added to the slurry. The reflectant was applied with a high pressure-high volume spraying rig developed by the Univ. of Nebraska Agricultural Engineering Department. A total of $17.9 \mathrm{~g}$ Celite 209 per $\mathrm{m}^{2}$ ground surface was applied in two applications on each treatment date.

Measurement of Leaf and Canopy Temperature. The average temperature of leaves in each plot was measured with six thermocouple junctions connected in parallel and glued with Acraseal ${ }^{\circ}$ to the lower side of six leaves located in the upper half of the plant canopy. These differential thermocouples were referenced against a single thermocouple which measured air temperature over the crop with a resolution of $0.25 \mathrm{C}$. Temperature differences were measured with a resolution of $0.025 \mathrm{C}$. The thermocouples were constructed of 30-gauge copper-constantan wires.

Radiative canopy temperatures were measured, as well, with a Barnes ${ }^{7}$ IT-3 S/30 IR thermometer. Resolution of this sensor was $0.5 \mathrm{C}$. The Barnes IT-3 was mounted with other radiation -sensors on the end of a boom extending about $4 \mathrm{~m}$ from a mast located at the common corner (F) of the plots containing the Treated and Untreated plants of Amsoy and Beeson cultivars (Fig. 1). Mounted $1 \mathrm{~m}$ above the canopy, the Barnes IT-3 viewed an area $12 \mathrm{~cm}$ in diam. The boom was moved manually from one plot to another. A scanning cycle over each plot was completed in about $2 \mathrm{~min}$. Two scanning cycles were completed hourly. The output from all instruments was logged with an automatic metcorological data recording system.

Recorded voltages of all temperature and radiation sensors were transformed into appropriate units through a set of programs written in Fortran IV. All radiation and temperature data were graphed on an $\mathrm{x}$-axis of time by a Calcomp Plotter using the program for plotting time dependent data developed by Brown and Rosenberg (1969).

Measurement of Reflectorized Board Temperature. Two wooden units were constructed in 1972 for a preliminary study of the reflectant effect on the temperature of inanimate objects. Each unit consisted of a $0.4 \times 5.7 \times 40.0 \mathrm{~cm}$ 3.ply plywood nailed to a $1.9 \times 6.0 \times 40.0 \mathrm{~cm}$ wooden board base. The plywood was separated from the base by three $1.0 \times 2.0 \times 5.7$ $\mathrm{cm}$ styrofoam spacers. Both units were painted green, at first, for a crude simulation of leaf color. Then one board was coated with Celite 209. The boards were placed at a height of $1 \mathrm{~m}$ inside an untreated soybean field a few centimeters above the crop canopy.

Four 30-gauge copper constantan thermocouple junctions, wired in parallel, were glued with epoxy very close to the upper surface of the plywood before painting the boards. Holes

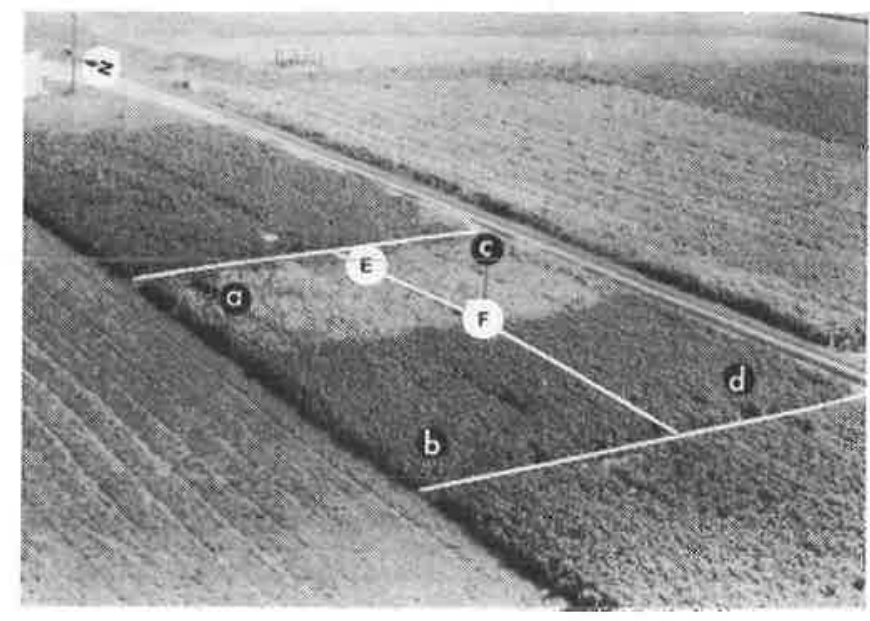

Fig. I. Aerial view of Agricultural Meteorology Lab. experimental fields at Mead, Neb. Laboratory building upper left, main experimental field right of roadway, radiation study field in foreground. a, Amsoy treated; b, Amsoy un. treated; c, Beson treated; d, Beeson untreated; e, location of pyranometer; $f$, location of boom holding all other radia. tion sensors. 
were first drilled in the plywood to facilitate placement of the thermocouples. The thermocouples in the Celite 209-treated board were wired differentially to those on the green board. The resolution of the differential thermocouple thus established was $0.025 \mathrm{C}$.

Air temperature was measured with thermocouples $200 \mathrm{~cm}$ above the ground at a location $55 \mathrm{~m}$ northeast of the boards. Temperature measurements were made at 15 -min intervals during the period 11 to 19 Aug. 1972.

Calculation of Canopy Temperature. Crop canopy temperature (T) was determined using an equation due to Fuchs and Tanner (1966):

$$
\mathrm{T}=\left[\frac{\sigma\left(\mathrm{T}_{\mathrm{bc}}\right)^{4}-\left(1-\epsilon_{\mathrm{c}}\right) \mathrm{B}}{\epsilon_{\mathrm{c}} \sigma}\right]^{1 / 4}
$$

where $T_{b c}$ is the apparent canopy temperature (measured with the IR thermometer), $\mathrm{B}^{*}$ is the flux density of downward directed 8 to $14 \mu$ radiation and $\varepsilon_{\mathrm{c}}$ is crop emissivity.

A reference plate, with known 8 to $14 \mu$ emissivity $\left(\varepsilon_{\mathrm{p}}\right)$ and temperature $\left(T_{p}\right)$ measured with thermocouples embedded near the surface, was viewed with the IR thermometer in order to calculate $B^{*}$ as follows:

$$
\mathbf{B}^{*}=\frac{\sigma\left(\mathrm{T}_{\mathrm{bp}}\right)^{4}-\epsilon_{\mathrm{p}} \sigma\left(\mathrm{T}_{\mathrm{p}}\right)^{4}}{1-\epsilon_{\mathrm{p}}}
$$

where $T_{b p}$ is the apparent surface temperature $(\mathrm{K})$ of the plate measured with the IR thermometer.

Reflectant Emissivity Measurement. The emissivity of Celite 209 used in this study was determined by a procedure similar to that of Conaway and van Bavel (1966). The temperature reference plate, described above, was coated with the reflectant slurry, dried and heated in an oven. The plate, as it cooled, was viewed with the IR thermometer. The actual plate temperature was measured simultaneously with thermocouples. The regression of $\sigma \mathrm{T}_{b p}^{i}$ on $\sigma \mathrm{T}^{i}$, was calculated. The slope of the regression line gave the emissivity of the dried Celite 209 which coated the plate.

Transpiration Measurement. Estimates of the transpiration rates from the treated and untreated crops were made by the Bowen ratio-energy balance (BREB) method. A discussion of the meteorological measurements required and the adjustments necessary to use this method are given in Blad and Rosenberg (1974). The parameters used in our calculations were obtained in the large field adjacent to the small plots (Areas A, B, C, D in Fig. 4).

\section{RESULTS AND DISGUSSION}

Leaf Temperature. Leaf temperature of the treated and untreated soybean cultivars was measured with thermocouples on 4 Aug. 1973. Results are shown in Fig. 2. Leaf temperature in both cultivars was increased by reflectant treatment. Treated Amsoy soybean leaves were warmer than untreated after about 0600 hours Solar Time (ST). Near solar noon the temperature difference between treated and untreated leaves was about 1 to $2 \mathrm{C}$. The pattern for the Beeson cultivar was similar, although differences between treated and untreated leaves were smaller.

Whether treated or not, leaves of the Amsoy cultivar were warmer than leaves in the corresponding Beeson cultivar treatments. The greatest temperature difference observed, about $3 \mathrm{C}$, was obtained during the afternoon between treated leaves of the two cultivars.

When the sun is near its zenith, vertical leaves absorb less global radiation than do horizontal leaves. Consequently, if incoming radiation is the only variable affecting leaf temperature, vertical leaves will be cooler than those which are horizontally positioned (Stevenson and Shaw, 1971). Since the more planophile Beeson leaves were cooler than those of Amsoy, it is apparent that factors other than incoming radiation were involved. As shown in the companion paper (Baradas et al., 1976) greater shortwave reflection and reduced net radiation were observed over the Beeson plot. Probably the reduced radiation load on the Beeson leaves accounted for the lower temperatures.

Temperature differences between cultivars were small from about 0700 to 1300 hours. Later in the day differences increased. This may have resulted, in part, from a change in Beeson canopy architecture which was observed. In the morning canopies of both cultivars appeared erectophile. As the day progressed the Beeson cultivar assumed a more planophile arrangement which reduced penetration of solar radiation into the canopy. It is probable that this change in canopy architecture also caused shading of lower

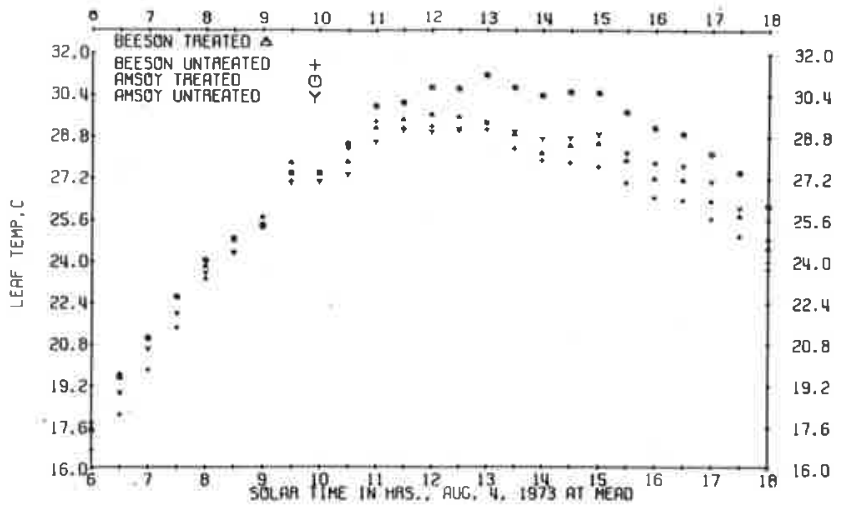

Fig. 2. Leaf temperature of Amsoy and Beeson soybean canopies on 4 Aug. 1973.

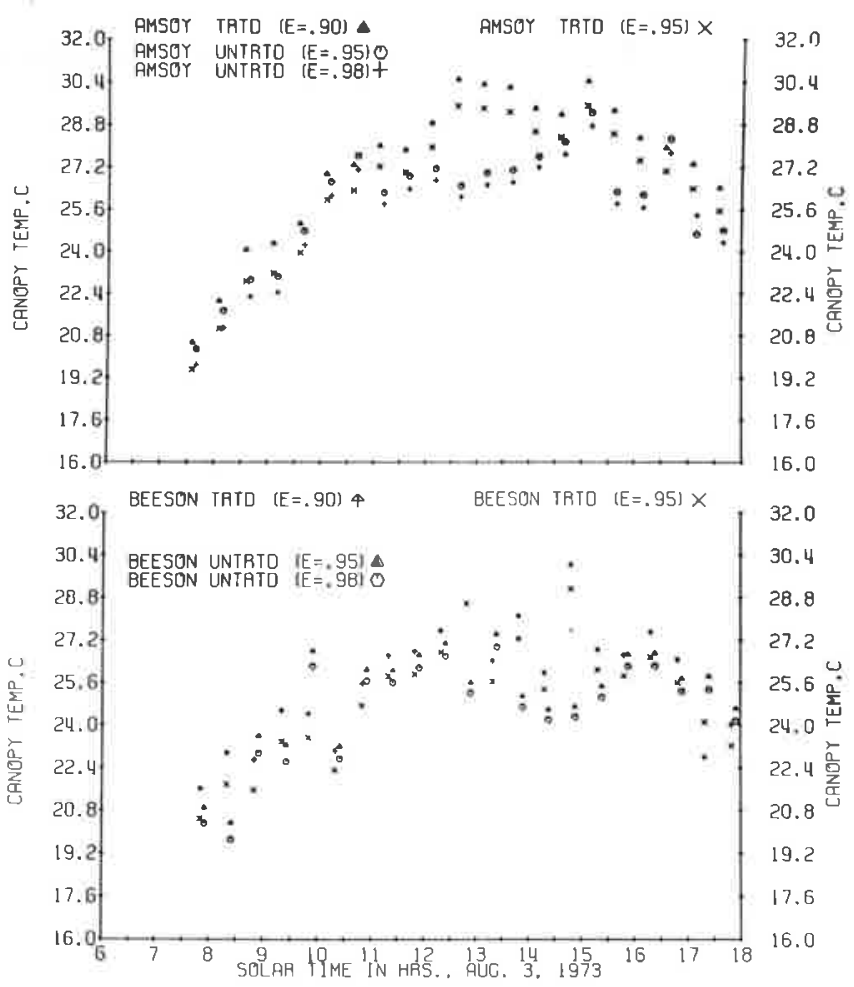

Fig. 3. Canopy temperature of Amsoy and Beeson soybeans on 3 Aug. 1973 based on assumed emissivities (E) for the 8 to $14 \mu$ waveband. 


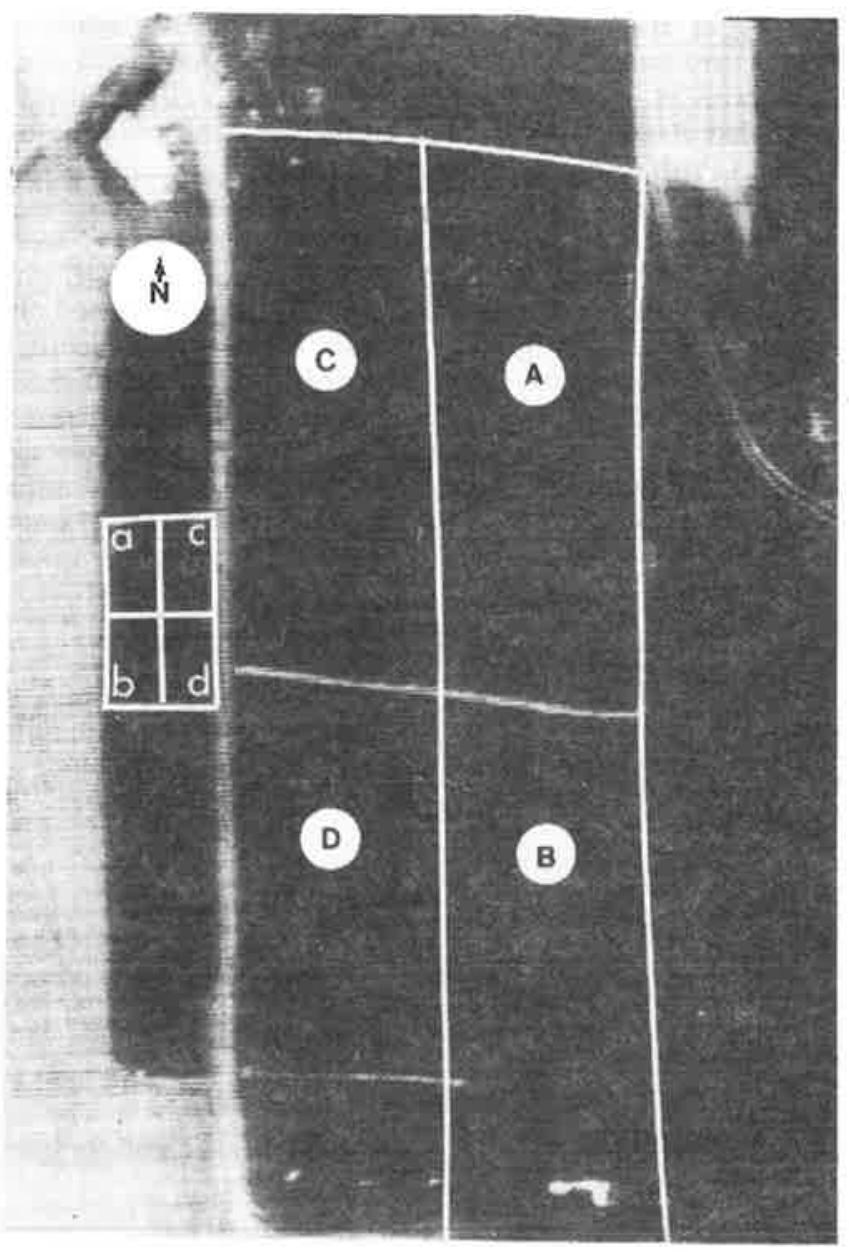

Fig. 4. Thermal scan of the fields on 31 July 1973. A, a Amsoy treated; B, b - Amsoy untreated; C, c - Beeson treated; $D, d$ - Beeson untreated.

Beeson leaves, including some to which thermocouples may have been attached.

Differences in leaf temperature between cultivars may also have been caused by differences in: (i) leaf area index (Beeson LAI 7.3, Amsoy LAI 6.5), (ii) leaf distribution and density (Beeson had greater leaf area in the upper part of the canopy), and (iii) elevation at which thermocouples were placed, since the cultivars differed in height (Amsoy $130 \mathrm{~cm}$, Beeson $120 \mathrm{~cm}$ ).

Canopy Temperature. An attempt in 1973 to measure the emissivity of the treated and untreated soybean canopies in the field was unsuccessful because of a failure in the Barnes IR thermometer. This failure was identified only in the computational stages of the work. Therefore, in the following analysis it is necessary to employ certain assumptions concerning plant emissivity.

The range of 8 to $14 \mu$ emissivity of untreated soybean canopies should be 0.95 to 0.98 , with the latter the more likely value. The measured emissivity of a continuous coating of Celite 209 was 0.89 . The treated canopy was incompletely covered by the reflectant. Therefore, we assume the emissivity of a coated canopy to range from 0.90 to 0.95 . The canopy temperature

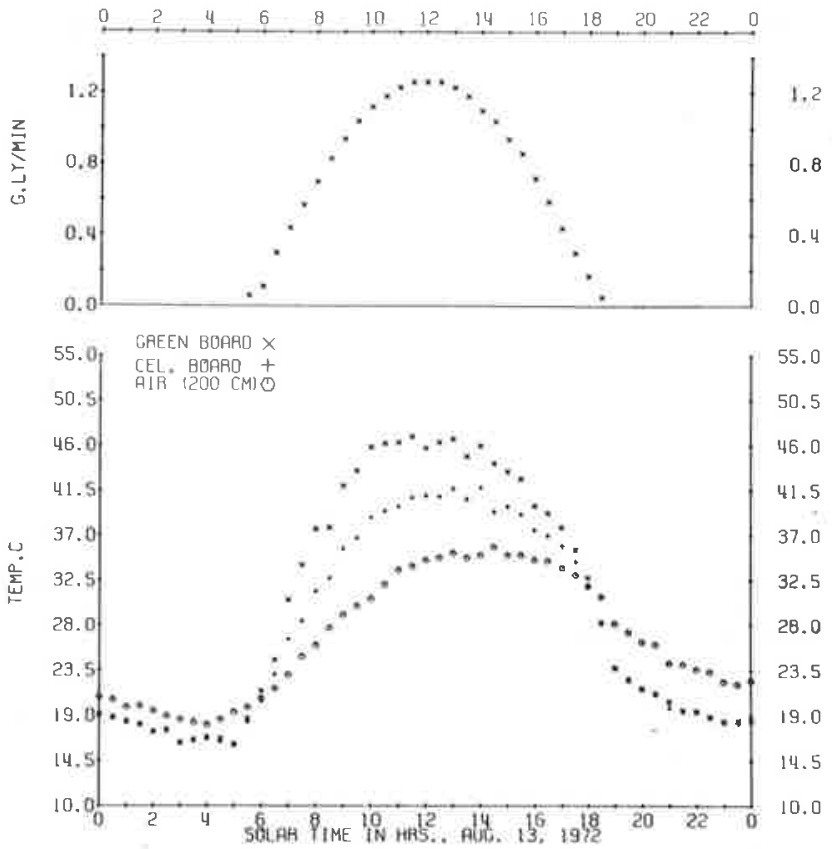

Fig. 5. Global radiation, air temperature $200 \mathrm{~cm}$ above ground and temperature of green-painted and Celite 209-coated wooden boards. 13 Aug. 1972 .

was computed by Eq. [2] using Barnes IR thermometer measurements made on 3 Aug. 1973. Results are presented in Fig. 3 for both the Amsoy and Beeson cultivars. Regardless of the emissivity assumed, treated canopies of both cultivars were generally 1 to $2 \mathrm{C}$ warmer than were untreated canopies. This pattern was true even if an emissivity of 0.95 is assumed for both treated and untreated canopies. Temperature differences were greatest in the early and mid-afternoon in the case of the Amsoy cultivar. In the Beeson cultivar differences were of about the same magnitude throughout the day.

A Nebraska Air National Guard reconnaissance plane with a Model AN/AAS-18 $8^{8}$ thermal scanner operating in the 10 to $14 \mu$ waveband overflew the fields near noon on 31 July 1973 . The thermal imagery (Fig. 4), analyzed with a densitometer, shows essentially the same flux density of outgoing longwave radiation from the treated and the untreated canopies. If the flux densities of incoming and outgoing longwave radiation are identical for two canopies, the canopy with a lower emissivity must be at a higher temperature (Eq. [2]). For example, let us assume an untreated canopy temperature of $28.6 \mathrm{G}$ with a flux density of incoming longwave radiation of $\mathbf{0 . 3 6}$ $1 \mathrm{y} / \mathrm{min}$ and an emissivity of 0.98 . Then, for the same flux densities of incoming and outgoing longwave radiation, the temperature of a treated canopy with emissivity of 0.95 and 0.90 would be 29.7 and $31.7 \mathrm{C}$, respectively.

The results of these aerial infrared scans corroborate our findings that the reflectant treatment led to an increase in leaf and canopy temperature rather than to the expected decrease.

\footnotetext{
${ }^{8}$ Texas Instruments, Inc. P.O. Box 1444, Houston, TX 77001
} 


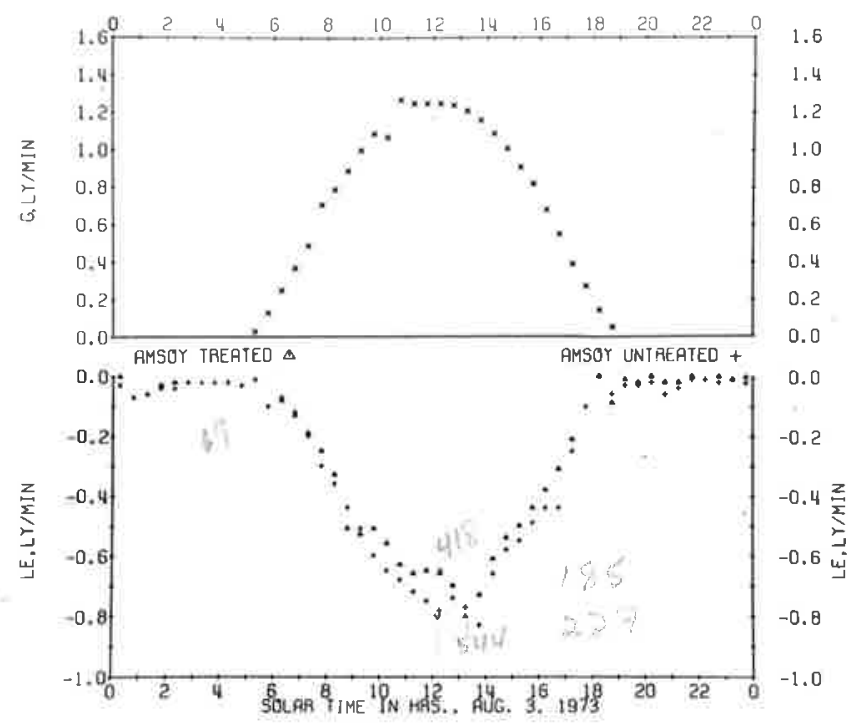

Fig. 6. Global radiation (G) and Bowen ratio-energy balance estimates of latent heat flux (LE) from reflectorized and untreated Amsoy soybeans at Mead, Neb. on 3 Aug. 1973.

Another test was made to determine reflectant effects on the temperature of an object. Two wooden boards were painted green and one was coated with Celite 209. Temperature of the boards was measured continually during the period 11 to 19 Aug. 1972. Typical data for a clear day are shown on Fig. 5. Both boards were at about the same temperature at night and were cooler than air at $200 \mathrm{~cm}$ above the ground. During the day the green board was warmer than the Celite-coated board and both were warmer than air.

Hudson (1969, p. 45) has shown that temperature of an object resulting from external energy sources is directly proportional to the ratio of the global radiation coefficient $(\alpha)$ to the longwave radiation emissivity $(\varepsilon)$. Since both boards were at about the same temperature during the night, we infer that their $\varepsilon$ values were nearly identical. The reflectorized board. undoubtedly, had a higher reflectivity and lower absorptivity for global radiation; hence a correspondingly lower $(\alpha / \varepsilon)$ ratio and a lower daytime temperature than the green board.

The $(\alpha / \varepsilon)$ ratios of the treated and untreated crops provide evidence for the observed temperature patterns. Global reflection coefficients ( $r$ ) reported in Baradas et al. (1975) are 20.7, 19.4, 24.5, and 21.2\% for Amsoy treated, Amsoy untreated, Beeson treated, and Beeson untreated, respectively. We have transmission data indicating that about $18 \%$ of the 400 to $1500 \mathrm{~nm}$ radiation is transmitted through an untreated soybean leaf and $11 \%$ through a treated one. With these transmission and reflectant coefficients and assuning $\varepsilon$ values of 0.97 and 0.91 for the untreated and treated leaves we calculate the following $(\alpha / \varepsilon)$ ratios for Amsoy treated, Amsoy untreated, Beeson treated, and Beeson untreated canopies: $0.75,0.65,0.72$, and 0.63. These ratios suggest that temperature of the treated crop should be warmer than that of the untreated crop. The treated Amsoy canopy should also be warmer than the corresponding Beeson canopy. It

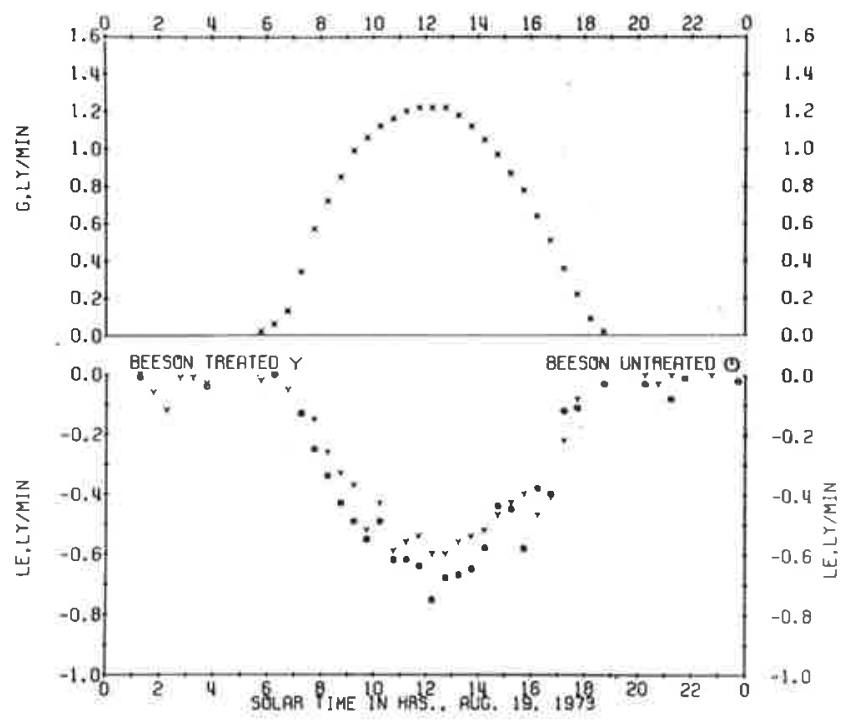

Fig. 7. As Fig. 6 for Beeson soybeans on 19 Aug. 1973.

is apparent that the lower $\varepsilon$ reduces the cooling rate and increases the temperature of the treated crop.

The increase in temperature of the treated crop may also be due, in part, to the reduction in transpiration from the treated crop. Evidence for the reduced transpiration from the reflectorized crop is provided by BREB estimates of evapotranspiration (ET). Fig. 6 is an example of the latent heat flux observed from the treated and untreated Amsoy canopy. Fig. 7 is a similar plot for the Beeson canopy. In both cases, it is evident that ET rates were lower from the treated crops. Generally, based upon ET rates for the 06 to 18 hour period, the reflectorized crop used about 10 to $15 \%$ less water than did the untreated crop. Soil moisture measured by gravimetric and neutron probe techniques also showed reduced water loss from the reflectorized crop.

\section{SUMMARY AND CONCLUSIONS}

Leaves and canopies of Amsoy and Beeson soybeans which had been treated with a reflectant, Celite 209, were warmer during daytime than those which were not treated. The reflectant reduced the emissivity of the crop which resulted in a reduced cooling rate and in an increased $(\alpha / \varepsilon)$ ratio. This is probably the major factor responsible for the increased temperature.

Evapotranspiration rates of the treated crop were about 10 to $15 \%$ lower than for an untreated crop. The reduction in ET rate likely contributed to the higher temperature of the reflectorized crop.

\section{ACKNOWLEDGMENTS}

We are grateful to Drs. R. Lemeur and S. B. Verma and Messrs. D. E. Sandin, R. Suverkrubbe, and J. Hines of the Univ. of Nebraska, Agricultural Meteorology Section, for their technical ansistance in the study and to Mrs. R. Sandhorst and Miss I.. Larsen for typing the manuscript. This research was supported by Grant G.A-24137, Itmospheric Sciences Section, National Science Foundation. Johns-Mlanville Products Corp., Denver, Colo. provicled the Celite 209 used in this study. Thanks are icndered to the Nebraska Air National Guard for the thermal scan in Fig. 4. 


\section{LITERATURE GITED}

Baradas, M. W., B. L. Blad, and N. J. Rosenberg. 1976. Reflectant induced modification of soybean canopy radiation ba. lance. V. Longwave radiation balance. Agron. J. 68:848-852.

Bartholic, J. F., L. M. Namken, and C. L. Wiegand. 1972. Aerial thermal scanner to determine temperatures of soil and of crop canopies differing in water stress. Agron. J. 64:603-608.

Biad, B. L. 1974. Lysimetric calibration of the Bowen ratioenergy balance method for evapotranspiration estimation in the central Great Plains. J. Appl. Meteorol. 13:227-236.

Brown, K. W., and N. J. Rosenberg. 1969. Computer program for plotting time dependent data with instruction and examples. Univ. of Nebr. College of Agric. Misc. Publ. 23.

Conaway, J., and C. H. M. van Bavel. 1966. Remote measurement of surface temperature and its application to energy balance and evaporation studies of bare soil surface. US Army Electronics Command, Atmospheric Sci. Lab., Research Div., Fort Huachuca, Ariz. Tech. Rep. ECOM, 2-67p-1. 136 p.

Doraiswamy, P. C., and N. J. Rosenberg. 1974. Reflectant induced modification of soybean canopy radiation balance. $i$. Preliminary tests with a kaolinite reflectant. Agron. J. 66: 224-228.
Fuchs, M., and C. B. Tanner. 1966. Infrared thermometry of vegetation. Agron. J. 58:597-601.

Gates, D. M., and W. Tantraporn. 1952. The reflectivity of deciduous trees and herbaceous plants in the infrared to 25 microns. Science 115:613-616.

Hucison, R. D., Jr. 1969. Infrared System Engineering. John Wiley \& Sons, Inc., New York. 642 p.

Lemeur, R., and N. J. Rosenberg. 1975. Reflectant induced modification of soybean canopy radiation balance. III. A comparison of the effectiveness of Celite and kaolinite reflectants. Agron. J. 68:30-35.

Rosenberg, N. J., and K. W. Brown. 1973. Measured and modeled effects of microclimate modification on evapotranspiration by irrigated crops in a region of strong sensible heat advection. Proc. UNESCO Symposium on Plant Response to Climatic Factors. Uppsala, Sweden, 1972. Ecol. Conserv. 5:539-545.

Seginer, I. 1969. The effect of albedo on evapotranspiration rate. Agric. Meteorol. 6:5-31.

Sellers, W. D. 1965. Physical climatology. Univ. of Chicago Press, Chicago. $272 \mathrm{p}$.

Stevenson, K. R., and R. H. Shaw. 1971. Effects of leaf orientation on leaf resistance to water vapor diffusion in soybean leaves. Agron. J. 63:327-329. 
